\title{
INRAe
}

Low-flow forecasting in France Update on the latest developments of the PREMHYCE operational forecast platform

Bourgin, F., Tilmant, F., Véron, A.-L., Besson, F., François, D., Le Lay, M., Nicolle, P., Perrin, C., Rousset, F., Thiéry, D., Willemet, J.-M., Magand, C., and Morel, M.

EGU21-2856 - https://doi.org/10.5194/egusphere-egu21-2856 premhyce@inrae.fr 


\section{> Motivation}

Early anticipation of low-flow periods is needed to improve water management

- In France in 2013: 73\% of total withdrawals

17 October 2018 from rivers

- Water uses affected by water shortages in rivers

- Climate change: perspectives of more severe summer low flows

- Lack of forecasting tool at national scale

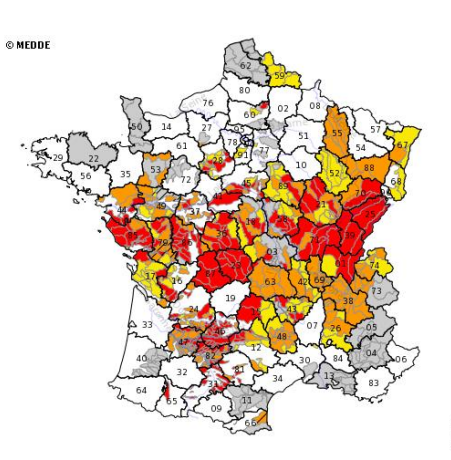

Vigilance

Vigilance

Alert

Reinforced alert

Crisis
1 October 2019

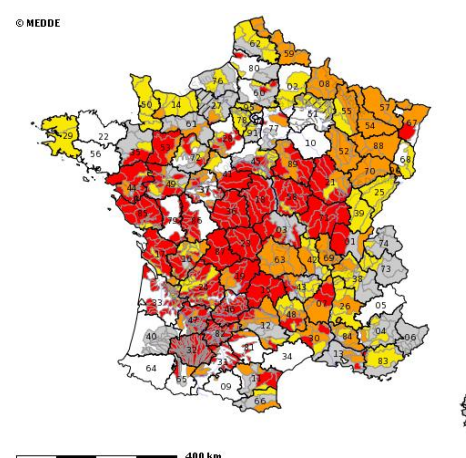

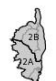

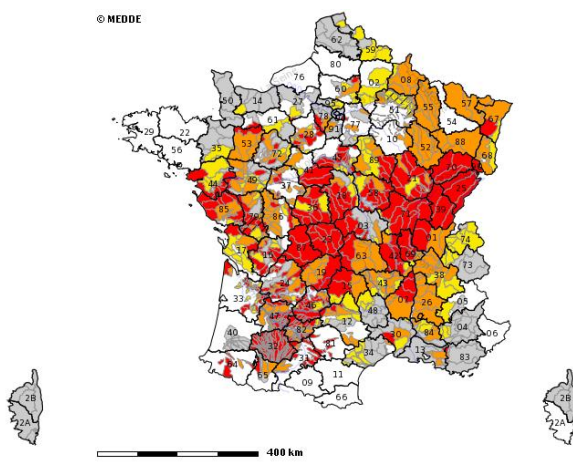

Restrictions in water use due to drought 


\section{> How to forecast low flows using hydrological models?}

1. Initialization

- Streamflow simulation by the model over a past period prior to the date $d$, using climate observations over this period.

- At time $d$ : available model state variables, resulting from the integration of past conditions and representing the basin's potential to generate runoff

3. Forecast

- From the previously determined initial conditions, model simulations of streamflows over the forecast period, using a weather forecast scenario derived or a climate archive

- Simulation of future streamflow from $d+1$ to $d+L$

- Step repeated for each available scenario, starting each time with the same initial conditions at $d$

- An ensemble of streamflow forecasts is generated, each member of this set being relative to a given scenario.
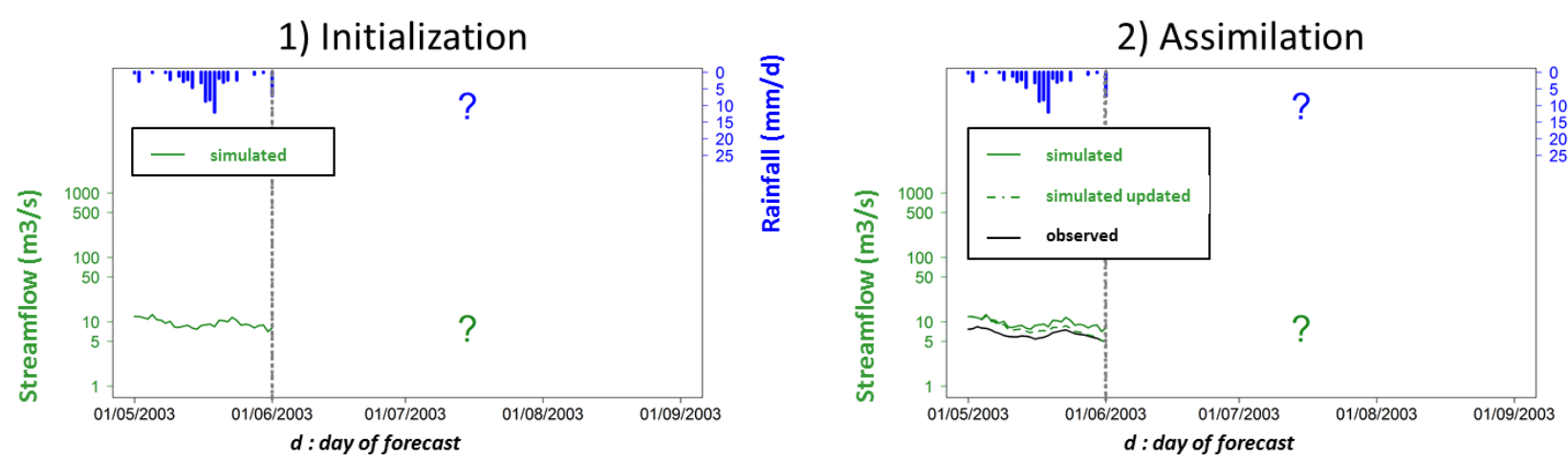

2. Assimilation (also called updating) - Use of the observed streamflow data to correct the model errors at time $d$, typically a difference between the observed and simulated values of flow at this time

- Appropriate assimilation approaches to minimize these errors, for example by updating model internal states, thereby generating an updated state vector

- This step of assimilation is not systematically implemented in all models
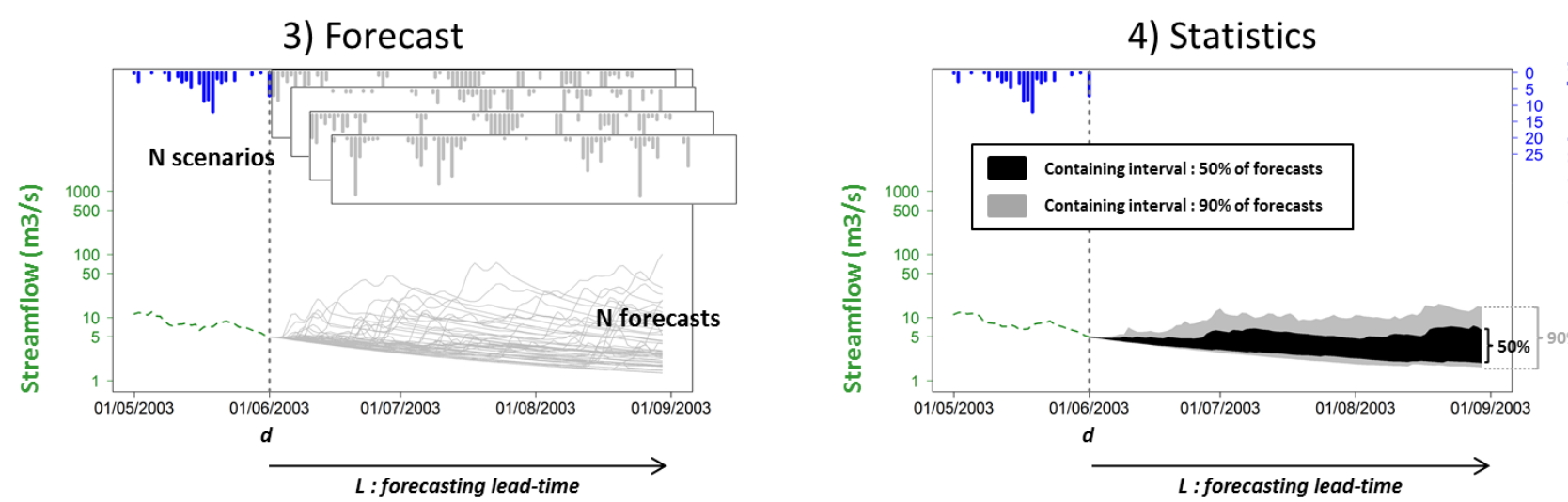

4. Statistical processing

- Statistical analysis of the members of the hydrological forecast to determine probabilities of being under low-flow thresholds

Post-processing approaches to correct the observed average model bias over a long time period (e.g. a systematic overestimation of low flows) 


\section{> Data and hydrological models}

- 5 hydrological models

- Simple multi-model approach

\section{- Observed data}

- Daily streamflow from national database with real time updates

- Daily climate variables from MétéoFrance with real time updates

- Forecast scenario

- Traditional ESP - 90-day horizon

- ECMWF forecasts processed by Météo-France - 14-day horizon
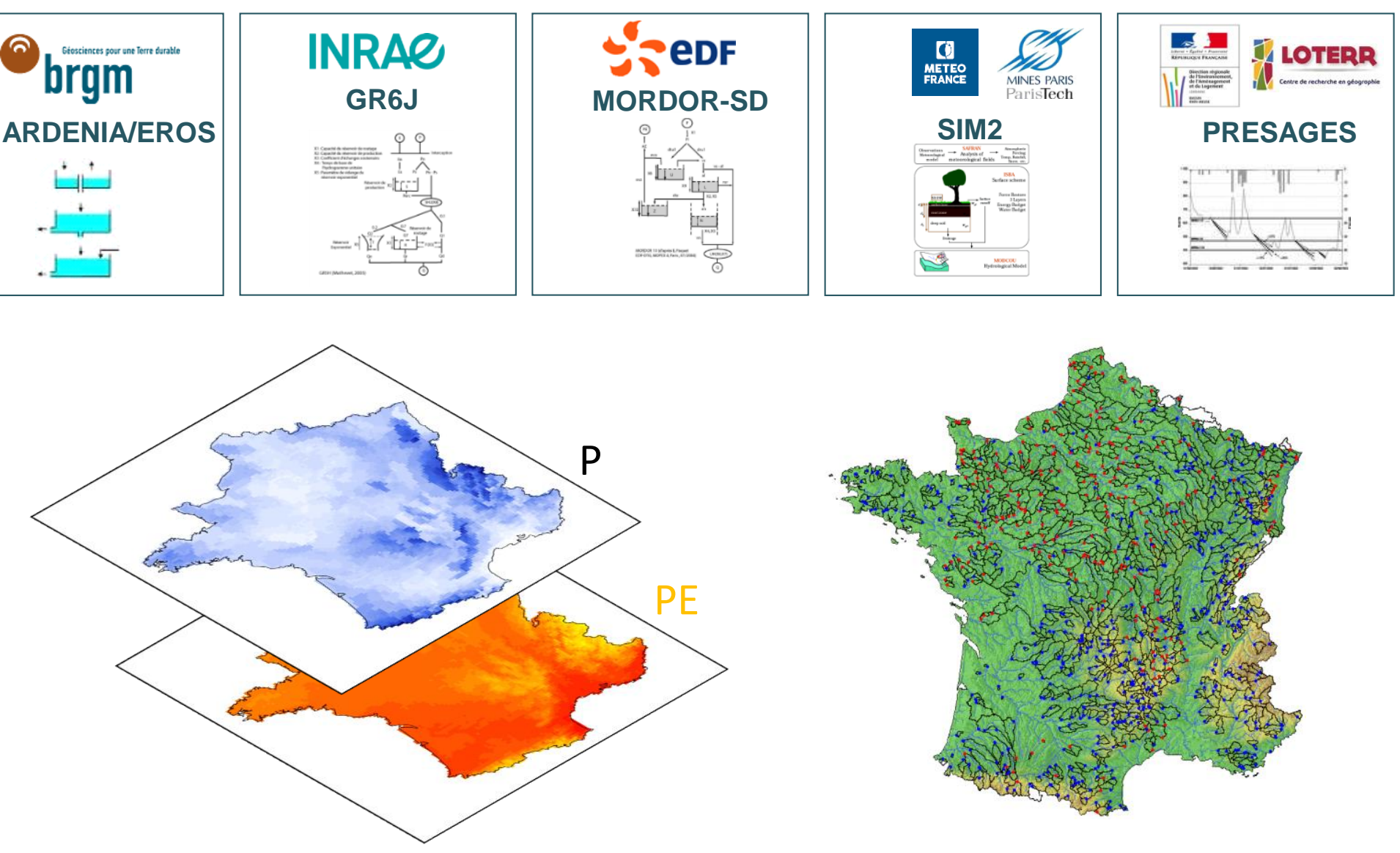

312 catchments for 22 operational users

More than 800 catchments (various regimes) for nation-wide outlook 


\section{> Real-time forecast results}

Summary sheet for a catchment and a model

\section{Summary sheets and text files}

\begin{tabular}{|c|c|c|c|c|c|}
\hline \multicolumn{2}{|c|}{ Bassin : La Bresle à Ponts-et-Marais [Pont.. } & \multirow{2}{*}{\begin{tabular}{|l|} 
Code HYDRO \\
Date de prevision \\
\end{tabular}} & \multirow{2}{*}{$\begin{array}{l}\text { G040202020 } \\
01 / 07 / 2020 \\
\end{array}$} & \multirow{2}{*}{$\begin{array}{l}\text { Source PREV } \\
\text { Echeance prev. (jours) }\end{array}$} & \multirow{3}{*}{$\begin{array}{l}\text { HIST-SA } \\
\infty 0 \\
\end{array}$} \\
\hline Modele hydro & GRQJ & & & & \\
\hline Seuils & Viglance $\left(\mathrm{m}^{2} / \mathrm{s}\right): 5.40$ & Alerte $\left(\mathrm{m}^{7} / \mathrm{s}\right): 4.70$ & Aletere renf $\left(m^{\prime} / s\right): 4.4$ & Crise $(m / s): 4.00$ & \\
\hline
\end{tabular}

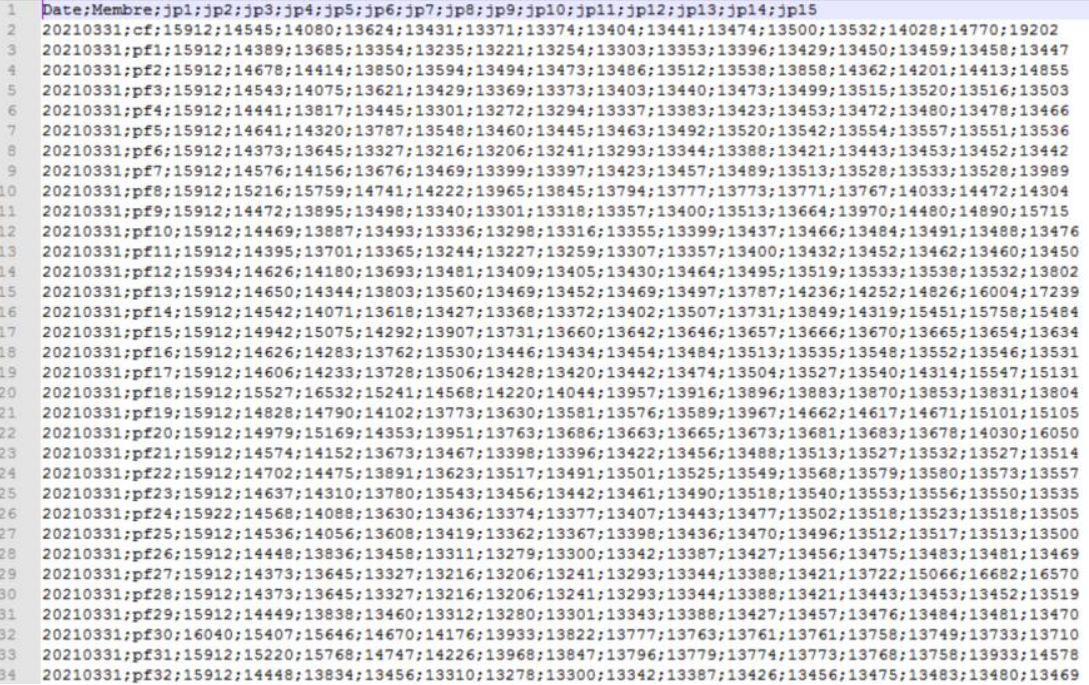

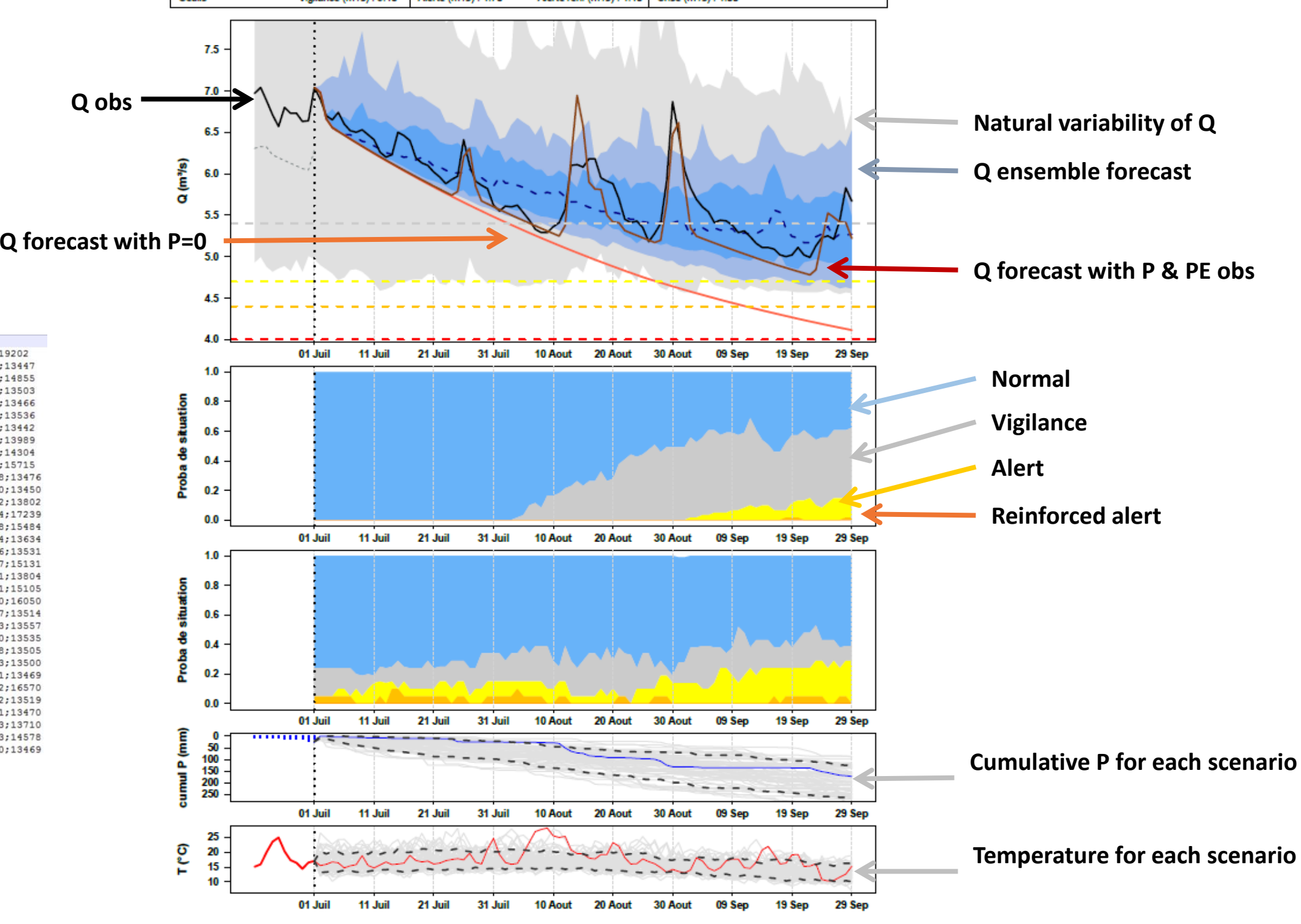




\section{> Real-time forecast results}

Shiny app for visualisation

- Selection of gauging stations for each user

- Monitoring or forecasting

- ECMWF or ESP

- Selection of a hydrological model

- Slider for forecasting horizon https://sunshine.irstea.fr/app/premhyce (restricted access)
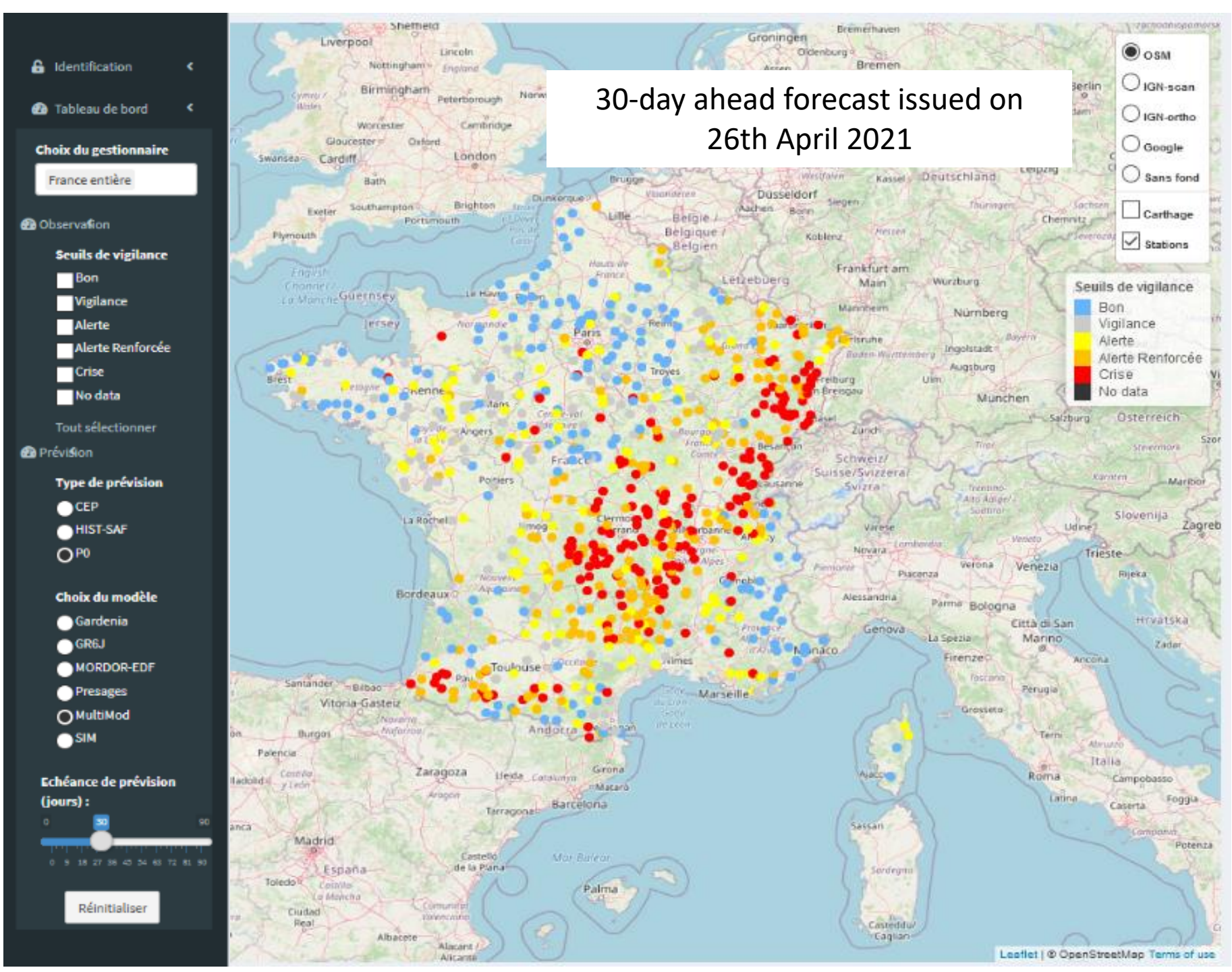
Standardized Index for Precipitation (SPI) and Streamflow (SSI) - 414 catchments

- 2020 Precipitation: Moderately dry to extremely dry in the North

- 2020 Discharge: Moderately dry thanks to wet conditions in winter
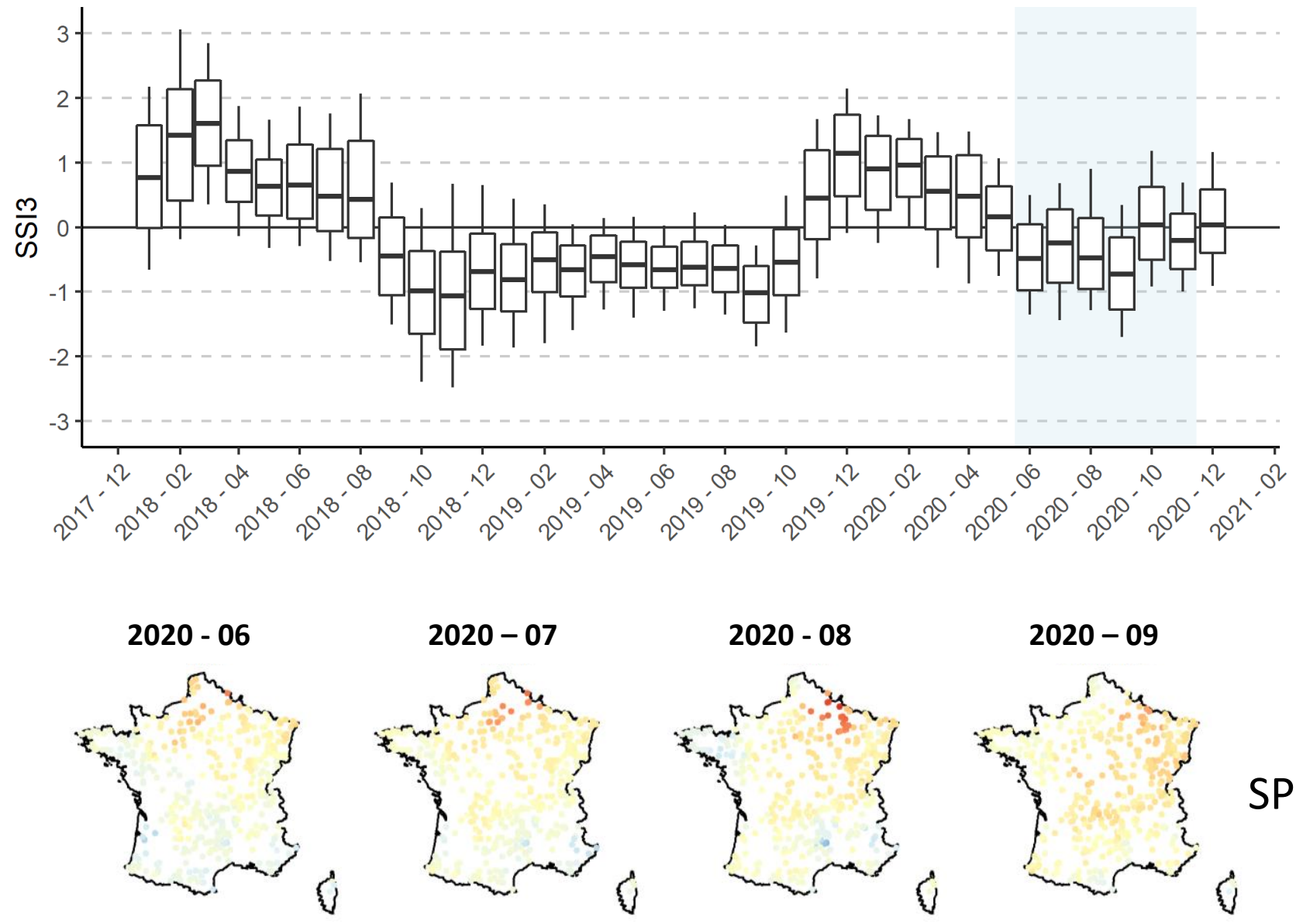

2020-09
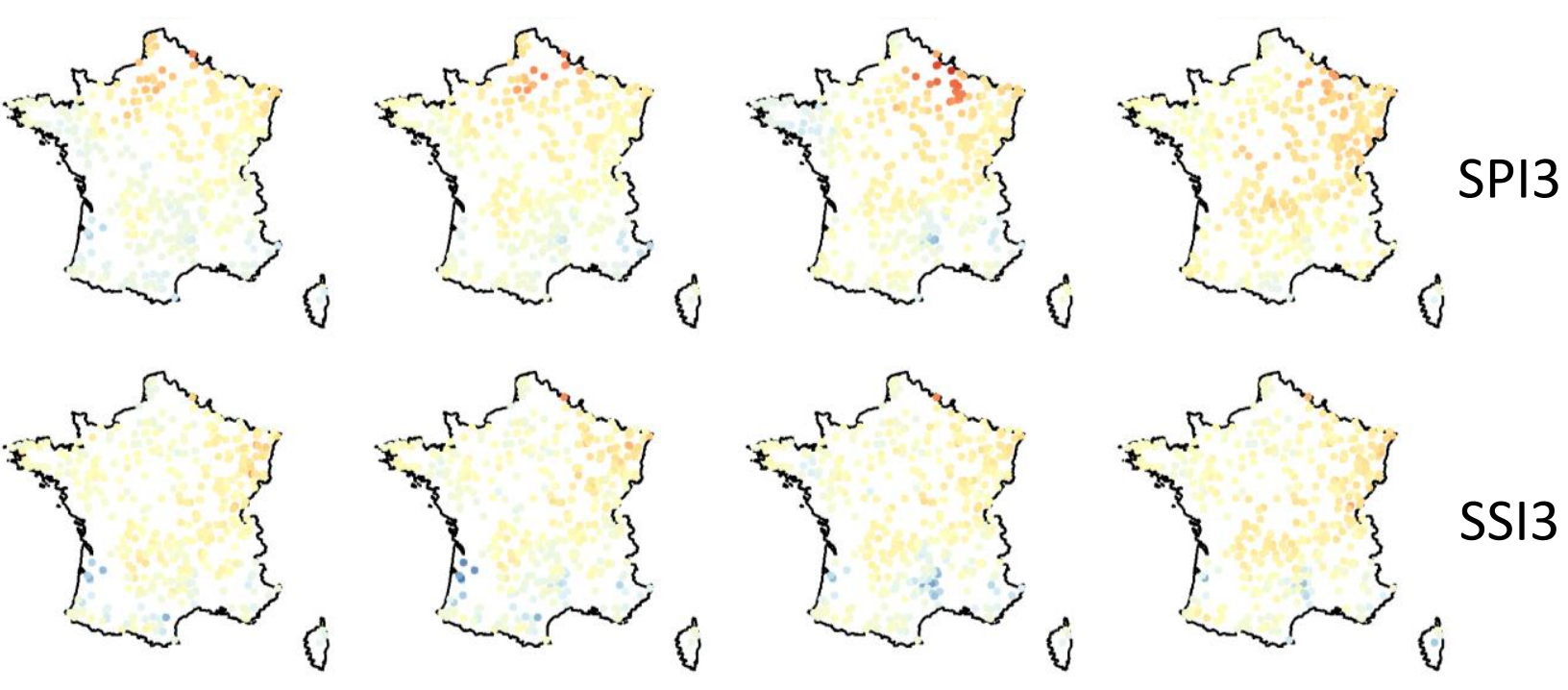


\section{> 2020 drought}

Performance assessment of the multi-model forecasting system - work in progress

\section{MAM7 : mean annual minimum for 7 days}

- Relatively good forecasts despite some overestimation

- ECMWF performs better than ESP

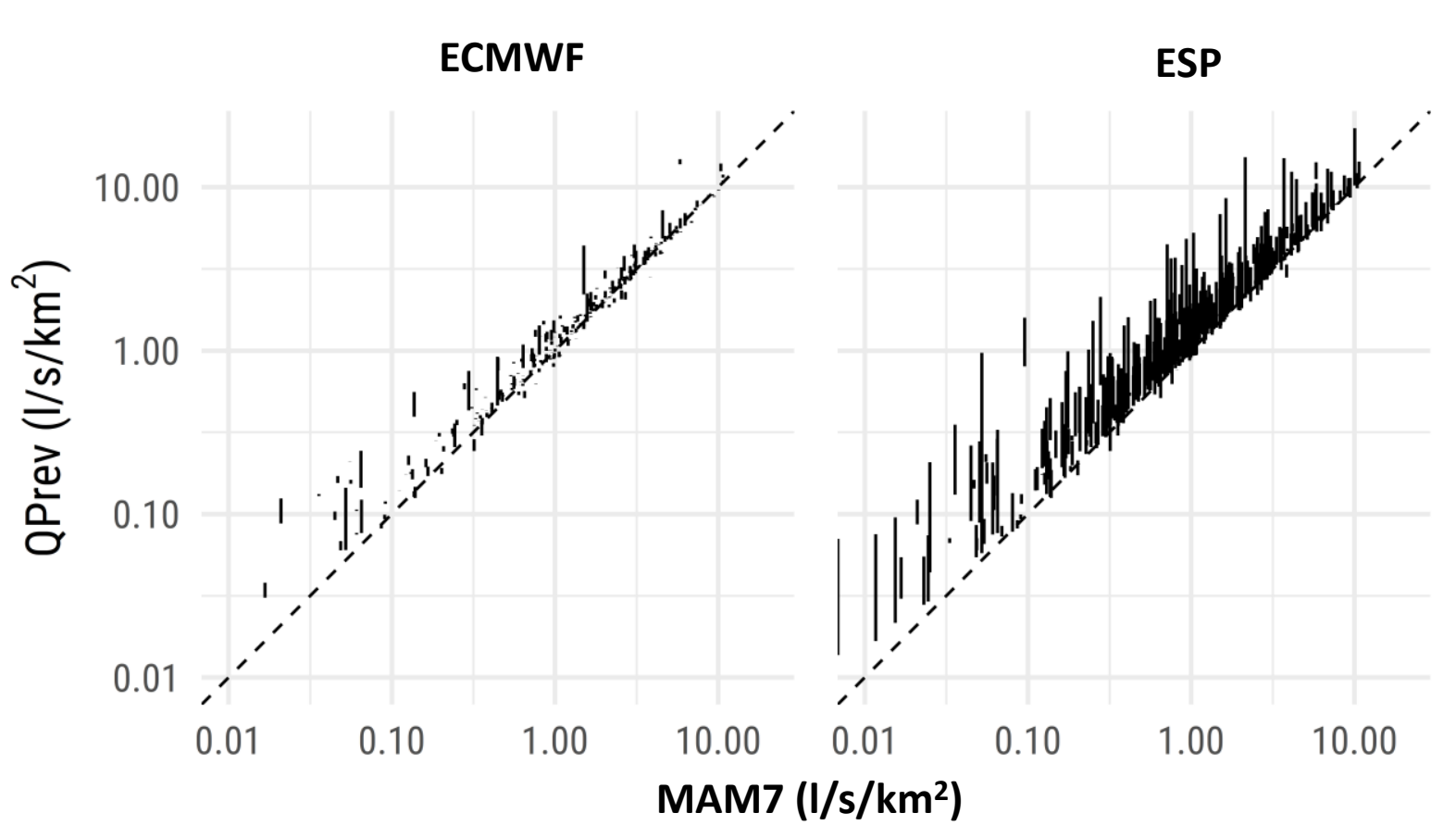

\section{MAM7 forecasts with ECMWF}

- No clear regional pattern

- Failures for some catchments

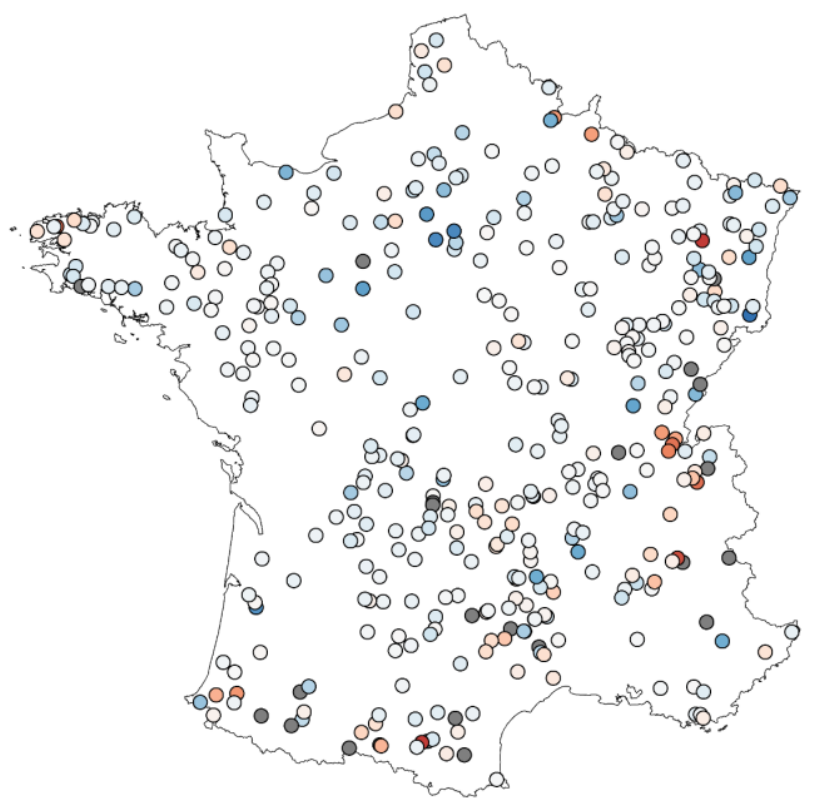




\section{> Methodological developments in a new project}

CIPRHES - French ANR project (2021 -2025) - https://www6.inrae.fr/ciprhes

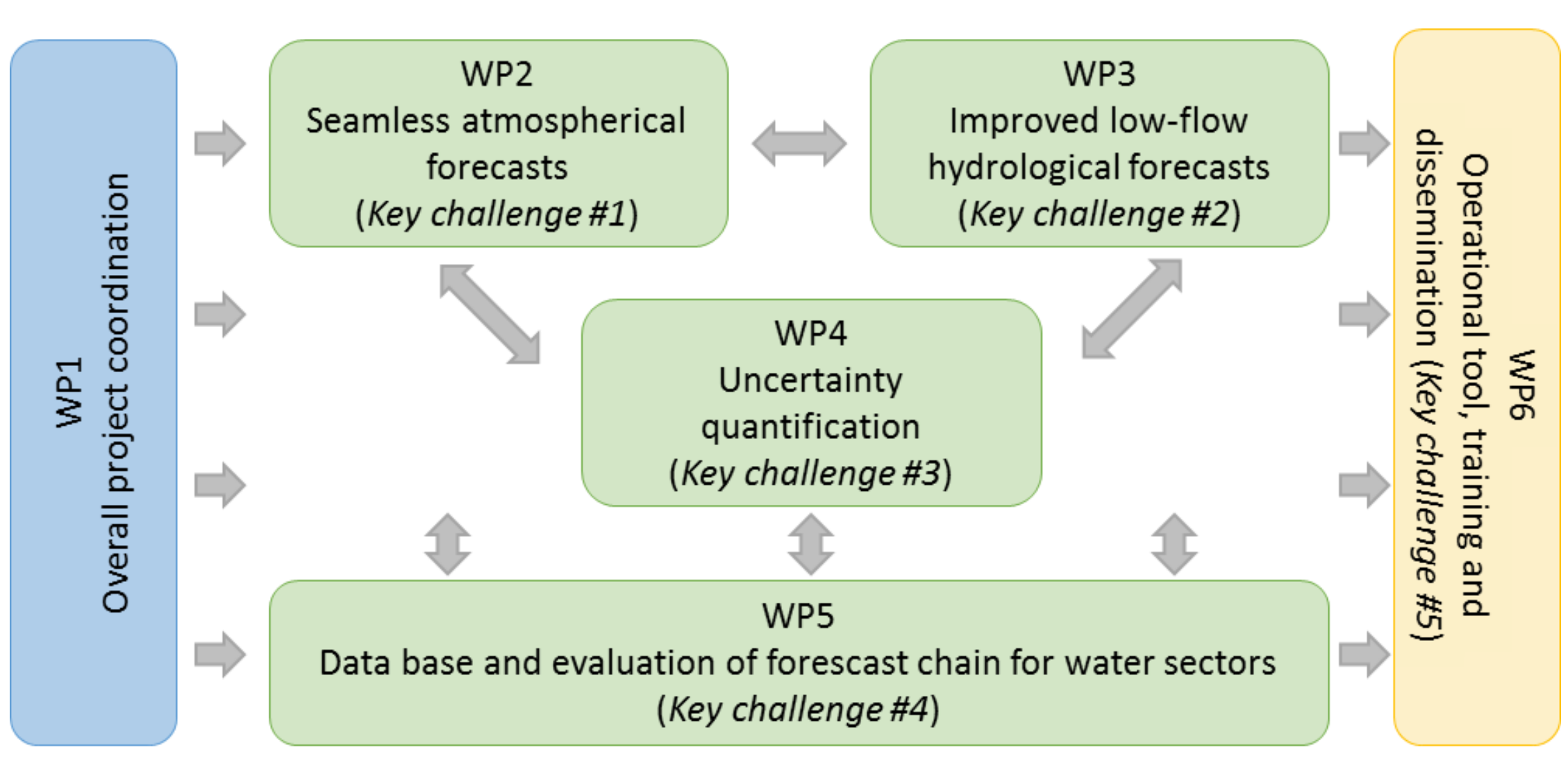

INRAC

Obrgm

$\therefore$ eDF

LOTERR

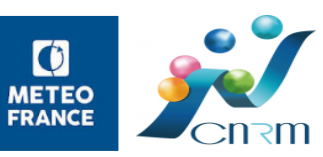

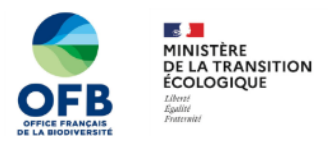

